\title{
Conhecimento especializado de licenciandos em Matemática no contexto de práticas formativas para inclusão
}

\author{
Specialized Knowledge of licensors in Mathematics in the context of formative practices \\ for inclusion
}

\author{
Gabriela Gomes Ribeiro ${ }^{1}$ \\ Eliane Matesco Cristovão ${ }^{2}$
}

\begin{abstract}
Resumo
Este artigo relata resultados parciais de uma pesquisa de mestrado de abordagem qualitativa, que investiga, em duas disciplinas dedicadas à prática como componente curricular, com enfoque no ensino da Matemática na perspectiva inclusiva, o Conhecimento Especializado do Professor de Matemática mobilizado por licenciandos nessas práticas. A coleta de dados utilizou audiogravações e materiais produzidos pelos licenciandos. A análise, fundamentada no referencial do Conhecimento Especializado do Professor de Matemática, evidenciou a importância de práticas formativas na perspectiva inclusiva para que o licenciando articule conhecimentos matemáticos e conhecimentos pedagógicos de conteúdo com conhecimentos sobre Necessidades Educacionais Especiais, para um ensino inclusivo da matemática. Porém, possíveis lacunas relativas ao Conhecimento da Estrutura Matemática nessas práticas formativas indicam que as disciplinas específicas de Matemática devem abordar a prática como componente curricular.
\end{abstract}

Palavras-chave: Formação inicial; Inclusão; Conhecimento especializado do professor de matemática.

\begin{abstract}
This article reports partial results of a qualitative research master's research, which investigates, in two subjects dedicated to the practice as a curricular component, focusing on teaching Mathematics from an inclusive perspective, the Specialized Knowledge of the Mathematics Teacher mobilized by undergraduate students in these practices. Data collection uses audio recordings and materials produced by the licensors. The analysis, based on the framework of the Specialized Knowledge of the Mathematics Teacher, shows the importance of training practices in the inclusive perspective so that the licensee articulates mathematical knowledge and pedagogical content knowledge with knowledge about Special Educational Needs, for inclusive teaching of mathematics. However, the possible gaps related to the Knowledge of the Mathematical Structure in these training practices indicate that the specific Mathematics subjects should approach the practice as a curricular component.
\end{abstract}

Keywords: Initial training; Inclusion; Specialized Knowledge of the Mathematics Teacher.

Submetido em: 29/10/2020 - Aceito em: 02/03/2021 - Publicado em: 02/06/2021

${ }^{1}$ Licenciada em Matemática, em 2018, e Mestranda em Educação em Ciências pela Universidade Federal de Itajubá-MG, Brasil. Professora do Colégio Empreender, Brasil. Email: gabigr16@hotmail.com. ORCID: https://orcid.org/0000-0001-5824-4583

2 Doutora em Educação, em 2015, pela Universidade Estadual de Campinas. Professora Adjunta da Universidade Federal de Itajubá-MG, Brasil. Email: limatesco@unifei.edu.br. ORCID: http://orcid.org/00000002-3070-1030 


\section{Introdução}

Este artigo visa apresentar resultados parciais de uma pesquisa de mestrado, em andamento, que objetiva investigar o Conhecimento Especializado (Carrillo, Climent, Contreras \& Muñoz-Catalán, 2013) mobilizado por futuros professores de Matemática no contexto de práticas formativas na perspectiva inclusiva. A pesquisa envolveu duas disciplinas dedicadas à prática como componente curricular, cujo enfoque é o ensino de matemática na perspectiva inclusiva.

Os alunos da educação básica, constantemente, apresentam baixos índices de rendimento em avaliações externas, em especial quando o foco é a Matemática. Segundo Pacheco e Andreis (2018, p. 106), as dificuldades apresentadas pelos alunos na disciplina podem estar relacionadas diversos fatores. Essa problemática abrange os alunos com Necessidades Educacionais Especiais $(\mathrm{NEE})^{3}-$ com dificuldades acentuadas de aprendizagem ou limitações, vinculadas a causas orgânicas ou a disfunções, limitações ou deficiências; dificuldade de comunicação e sinalização; altas habilidades/superdotação (Brasil, 2001) -, mas também envolve aqueles sem essas dificuldades.

Assim sendo, cabe ao professor buscar caminhos que facilitem o aprendizado e utilizar atividades para a inclusão de todos os alunos no processo regular de ensino. Estas práticas inovadoras e mais inclusivas beneficiam a todos e não podem ser repensadas apenas para classes com alunos com NEE. Porém o professor precisa conhecer as limitações e as diferenças desses alunos, para atuar de forma mais inclusiva, propiciando desenvolvimento cognitivo e aprendizagem para todos. Evidentemente, precisa ser preparado e ter uma formação que lhe garanta conhecer leis e decretos sobre inclusão, além de lhe permitir vivenciar práticas inclusivas e desenvolvê-las para alunos em um contexto real (Ribeiro, 2018).

A Lei de Diretrizes e Bases da Educação, visa garantir aos alunos com NEE "professores com especialização adequada em nível médio ou superior, para atendimento especializado, bem como professores do ensino regular capacitados para a integração desses educandos nas classes comuns" (Brasil, 1996, p.44). Assim sendo, Passos, Passos e Arruda (2013, p. 5) afirmam: "cada curso de licenciatura deve proporcionar a seus acadêmicos conhecimentos a respeito das mais variadas necessidades educacionais especiais que eles possam vir a se deparar em sua futura ação profissional". Porém, segundo Souza (2016), a maioria das matrizes curriculares dos cursos de Licenciatura em Matemática não contém a temática da Educação Inclusiva.

Portanto, os cursos de Licenciatura em Matemática deveriam incluir, em suas matrizes, disciplinas que tratem dessa temática de modo articulado com a prática, como

\footnotetext{
${ }^{3}$ Existem legislações mais atuais acerca da inclusão (Brasil, 2011), porém o termo NEE, aqui utilizado, engloba a totalidade dos alunos que por algum motivo não acompanham a turma em que estão inseridos, como, por exemplo, aqueles com Transtorno de Déficit de Atenção com Hiperatividade (TDAH), atendidos pelos licenciandos no âmbito das práticas formativas.
} 
componente curricular. A propósito, aqui analisamos resultados de uma proposta de disciplina com esse foco, pensada e desenvolvida em 2019 pela pesquisadora, primeira autora, em parceria com a docente da disciplina, orientadora da pesquisa e segunda autora. $\mathrm{E}$ na próxima seção traremos o referencial utilizado, sobre conhecimento, e o percurso metodológico da pesquisa. Ao final faremos considerações a respeito dos dados analisados.

\section{Conhecimentos na formação de professores}

O precursor da ideia de Conhecimento Pedagógico de Conteúdo (PCK) foi Shulman (1987), que assume haver um conhecimento novo, produzido na sala de aula do professor, ao transformar os conhecimentos da base em diálogo com a prática: o PCK, que distingue o conhecimento de um professor do conhecimento de um especialista, ambos da mesma disciplina. Diante do trabalho de Shulman e de suas contribuições para o ensino com foco no PCK, alguns investigadores propuseram-se a criar modelos próprios de cada área, e isso incluiu a Educação Matemática.

Carrillo coordena um grupo conhecido como Seminario de Investigación em Didáctica de la Matemática (SIDM), composto por investigadores de várias universidades do mundo, com sede na Universidade de Huelva - Espanha, no qual estudam sobre o conhecimento profissional do professor de matemática. Flores-Medrano et al. (2016, p. 208, tradução nossa), membros do grupo, explicam esse trabalho:

$\mathrm{Na}$ investigação que desenvolvemos coletivamente no grupo do SIDM sobre o conhecimento profissional do professor de matemática, o trabalho com os modelos existentes tem permitido conhecer as suas limitações e potencialidades e, por consequência, tem nos levado a propor um modelo centrado no que é específico ao professor de matemática, deixando de lado aspectos do conhecimento que são compartilhados com professores de outras disciplinas.

Diante desses estudos, o grupo criou o modelo Mathematics Teacher's Specialized Knowlegde (MTSK). Eles entendem que o conhecimento do professor não se traduz apenas pelo domínio da Matemática, mas é permeado também pelo conhecimento pedagógico do conteúdo. Porém, antes do MTSK, um modelo específico para analisar os Conhecimentos dos Professores de Matemática já existia - o Mathematical Knowledge for Teaching - MKT (Ball, Thames \& Phelps, 2008) - e foi utilizado como principal referência do MTSK. De acordo com Flores-Medrano, Escudero-Ávila, Montes, Aguilar e Carrillo (2014, p. 71-72, tradução nossa), o MTSK surgiu "em resposta às dificuldades detectadas no MKT e toma como base as potencialidades deste e de outros modelos que caracterizam o conhecimento do professor de matemática".

Conforme Flores-Medrano et al. (2014, p. 71-72, tradução nossa), o MTSK “considera o caráter especializado do conhecimento do professor de forma integral em todas as suas subdimensões e evita remeter a referências externas (conhecimento de outras profissões)". Ademais, Ribeiro e Amaral (2015, p. 4, tradução nossa) assim reforçam essa ideia: "o conhecimento dos professores é percebido com suas particularidades associadas às especificidades das tarefas de ensino, considerando que tais tarefas são desenvolvidas com o 
DOI: $10.20396 /$ zet.v29i00.8661777

objetivo de permitir que os alunos entendam o que fazem, por que e para que servem". Os criadores do MTSK basearam-se nos dois grandes domínios do conhecimento (Conhecimento do Conteúdo e Conhecimento Pedagógico do Conteúdo) propostos por Shulman, porém com foco na Matemática. Assim, o MTSK é dividido em dois domínios: Conhecimento da Matemática, do inglês Mathematical Knowledge (MK) e Conhecimento Pedagógico da Matemática, do inglês Pedagogical Content Knowledge (PCK), que se subdividem em três subdomínios cada um, como mostra a Figura 1:

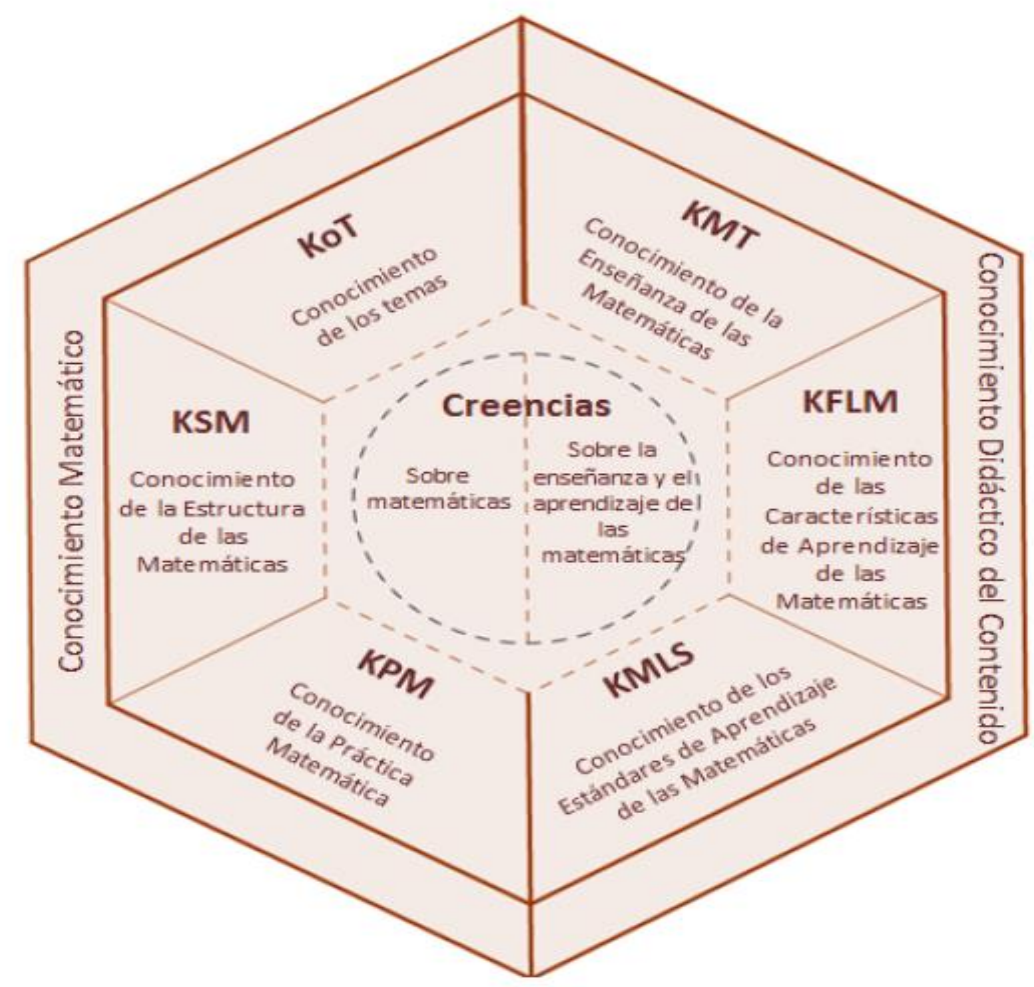

Figura 1 - Domínios e Subdomínios do MTSK

Fonte: Flores-Medrano et al. (2016, p. 209).

Os autores utilizaram as siglas em inglês, embora com seus significados em espanhol. Os domínios e subdomínios do modelo MTSK estão inter-relacionados e se alimentam mutuamente. Ao centro são consideradas as crenças dos professores. Segundo Bernardo et al. (2018, p. 116), "MK e PCK sustentam a prática do professor e ambos influenciam e são influenciados pelas crenças do professor". Exporemos aqui os dois domínios, seus subdomínios e sua relação com as crenças, de acordo com o modelo. Ao final, faremos a proposta de um novo subdomínio, que possibilita analisar conhecimentos específicos para o ensino da Matemática na perspectiva inclusiva, de forma articulada com os subdomínios existentes no modelo.

\section{MK: Mathematical Knowledge}

Este domínio engloba três subdomínios, que compõem e dão sentido ao Conhecimento Matemático (MK) do professor de matemática: Conhecimento dos Tópicos 
Matemáticos (KoT), Conhecimento das Estruturas Matemáticas (KSM) e Conhecimento da Prática Matemática (KPM).

\section{KoT: Knowledge of Topics}

Refere-se aos Conhecimentos dos Tópicos matemáticos do professor, e, de acordo com Flores-Medrano et al. (2016, p. 210, tradução nossa), “o conhecimento dos tópicos não se refere apenas ao conhecimento da matemática como disciplina, mas também inclui a matemática escolar". Segundo esses pesquisadores, o professor conhece os conteúdos matemáticos (conceitos, procedimentos, fatos, regras, teoremas) e seus significados, mas esse saber também inclui o conteúdo que deseja que o aluno aprenda com maior aprofundamento.

Segundo Flores-Medrano et al. (2014) são cinco suas características:

- Fenomenologia: Conhecimento do professor de modelos atribuídos a um tema e Conhecimentos de usos e aplicações de um tema.

- Propriedade e fundamentos: Conhecimento das propriedades e dos fundamentos atribuídos a um tópico ou procedimento específico.

- Registros de representação: conhecimento das distintas formas como pode representar um conteúdo (numérica, gráfica, verbal, analítica) e conhecimento da notação e dos vocabulários apropriados.

- Definições: conhecimento das definições de determinado objeto.

- Procedimentos: conhecimento de algoritmos, condições e fundamentos a serem utilizados.

\section{KSM: Knowledge of the Matematical Structure}

Trata do conhecimento das relações que o professor estabelece entre distintos conteúdos, segundo Flores-Medrano et al. (2014, p. 77, tradução nossa), "seja do curso que você está ministrando, seja com conteúdo de outros cursos ou níveis de ensino. Se trata especificamente de conexões entre tópicos matemáticos". Eles propõem quatro características de conexões matemática:

- Conexões de complexidade: relação entre os conteúdos ensinados e os posteriores.

- Conexões de simplificação: relação entre os conteúdos ensinados e os anteriores. Exemplo: Conexão entre o conteúdo de funções e o de conjuntos.

- Conexões de conteúdos transversais: relação entre os conteúdos simples e os complexos e os modos de pensamentos associados a eles.

- Conexões Auxiliares: relação com um elemento auxiliar em outro tema, isto é, conexão interconceitual.

KPM: Knowledge of Practices in Mathematics

Conforme Flores-Medrano et al. (2014), este domínio inclui o conhecimento de como se define a matemática; as diferenças entre uma demonstração, uma prova e uma comprovação; a capacidade de raciocinar matematicamente, conhecer distintos tipos de 
DOI: 10.20396/zet.v29i00.8661777

raciocínios e conhecimentos matemáticos e reconhecer a que contextos são adequados e fazer relações, correspondências e equivalência. São duas as características para este subdomínio:

- Práticas ligadas à matemática em geral: o conhecimento de como ela é desenvolvida de forma independente do conhecimento abordado fornece aos professores a estrutura do raciocínio lógico.

- Práticas ligadas a uma temática da Matemática. Caracteriza-se como sendo uma particularização da anterior, isto é, quando se tem um tema em específico.

\section{PCK: Pedagogial Content Knowledge}

O PCK é o segundo domínio e também se subdivide em três subdomínios: Conhecimento do ensino da Matemática (KMT), Conhecimento das características de aprendizagem da matemática (KFLM) e Conhecimento dos estândares de aprendizagem da Matemática (KMLS).

\section{KMT: Knowledge of Mathematics Teaching}

Envolve, conforme Flores-Medrano et al. (2016), o conhecimento do professor dos recursos, dos materiais e dos modos de apresentar o conteúdo e o seu potencial, e como do conhecimento de exemplos adequados para cada conteúdo. Flores-Medrano et al. (2014) indicam três, para melhor explicitar as ideias deste subdomínio:

- Teorias de ensino pessoais ou institucionalizadas: conhecimento de teorias de ensino específicas da Educação Matemática.

- Recursos materiais e virtuais: conhecimento dos recursos materiais e virtuais - livros, calculadoras, materiais, jogos, softwares - como elemento para o ensino de conteúdos matemáticos.

- Atividades, tarefas, exemplos, ajudas: conhecimento do professor acerca do objeto material ou virtual em si.

\section{KFLM: Knowledge of Features of Learning Mathematics}

De acordo com Flores-Medrano et al. (2016), este subdomínio e o anterior (KMT) compreendem o que se tem interpretado como o conhecimento especializado do professor de matemática quanto à forma como os alunos aprendem os conteúdos matemáticos. No KFLM são abordados os hábitos de raciocínio dos alunos em determinados conteúdos, suas dificuldades, os aspectos mal compreendidos por eles e os mais ou menos atrativos, relacionando-os às teorias de aprendizagem. Flores-Medrano et al. (2014) sugerem quatro características para simplificar as ideias deste subdomínio:

- Formas de aprendizagem: conhecimento do professor acerca dos possíveis modos de aprendizagem dos alunos, incluindo teorias de desenvolvimento cognitivo dos estudantes.

- Facilidades e dificuldades relacionadas à aprendizagem: conhecimentos sobre os erros, os obstáculos e as dificuldades associados à matemática em geral. 
- Formas de interação do aluno com os conteúdos matemáticos: conhecimento acerca dos processos e das estratégias dos alunos e do vocabulário utilizado para abordar um conteúdo.

- Concepções dos alunos acerca da matemática: conhecimento sobre suas expectativas e seus interesses em relação à matemática.

KMLS: Knowledge of Mathematics Learning Standards

É considerado por Flores-Medrano et al. (2014, p. 85-86, tradução nossa) o conhecimento do professor do que o aluno deve ou pode alcançar em um ano escolar ou alcançou em um ano anterior ou posterior - "é o que o professor sabe sobre as capacidades conceituais, procedimentais e de raciocínio matemático que são promovidas em determinados momentos educacionais". São três suas características:

- Conteúdos matemáticos necessários para ensinar: conhecimento dos conteúdos ensinados em cada série/ano, acessível em documentos oficiais (como a Base Nacional Comum Curricular - BNCC).

- Conhecimento do nível esperado de desenvolvimento conceitual e procedimental: conhecimento do desenvolvimento conceitual e processual esperado no aluno.

- Sequenciação dos temas: conhecimento da sequência de conteúdos em uma série/ano, ou em anos anteriores e posteriores.

As crenças no MTSK

Para Flores-Medrano et al. (2014), as crenças estão relacionadas ao perfil do professor investigado: seu modo de ver a matemática, o ensino e a aprendizagem influencia constantemente na pesquisa. As crenças estão no centro do modelo com linhas pontilhadas, pois, para Flores-Medrano et al. (2014), permeiam o conhecimento de cada subdomínio. Porém, eles não esclarecem o conceito de crença adotado e ponderam que elas não podem ser medidas. Por isso e por não serem o foco do estudo, neste trabalho não as levaremos em consideração.

Para relacionar os conhecimentos com as práticas formativas com foco na inclusão, criamos um novo subdomínio - que nomeamos CEMI -, que auxilie a identificar um Conhecimento específico para o Ensino da Matemática na perspectiva Inclusiva. Aqui o descrevemos.

CEMI: Conhecimento para o ensino de Matemática na perspectiva inclusiva.

Neste novo subdomínio, consideramos o conhecimento de recursos e métodos específicos para atender alunos com NEE, em especial aqueles meios que forem diferentes dos geralmente utilizados para alunos sem NEE, além de formas de organizar as tarefas ou de gerenciar a turma para garantir a inclusão, por exemplo, do aluno com Transtorno do Espectro Autista (TEA), que não consegue estabelecer contato visual e precisa de uma rotina predeterminada; ou do aluno com Transtorno de Déficit de Atenção com Hiperatividade (TDAH), que necessita de tarefas mais curtas e sequenciadas, para acompanhar as aulas. Esse 
conhecimento está associado aos outros do modelo e, portanto, quando for mobilizado, ele será apresentado de forma articulada aos demais.

A partir deste referencial e da adaptação das características apresentadas por Ribeiro (2020), foi possível compor um quadro para identificar e caracterizar os Conhecimentos mobilizados pelos licenciandos. Na próxima seção descreveremos o percurso metodológico da pesquisa, para, em seguida, apresentar as análises realizadas até o momento.

\section{Percurso metodológico}

Nesta pesquisa ${ }^{4}$, de caráter qualitativo, "a preocupação do pesquisador não é com a representatividade numérica do grupo pesquisado, mas com o aprofundamento da compreensão de um grupo social, de uma organização, de uma instituição, de uma trajetória etc.” (Goldenberg, 2004, p. 14). Dessa forma, seguindo os preceitos de Lüdke e André (2013), viabilizamos o estudo com dados descritivos pelo contato direto do pesquisador com o objeto de estudo, priorizando o processo, e não o produto.

Com disciplinas planejadas para oferecer várias experiências com práticas inclusivas, os licenciandos de uma turma do Curso de Matemática Licenciatura de uma universidade pública de Minas Gerais participaram ativamente do processo: definiram quais NEE gostariam de investigar, as abordagens e os materiais a serem utilizados e negociaram com escolas e professores os conteúdos dos planos de aula com foco na inclusão. Assim, podemos afirmar que a concepção e o desenvolvimento da disciplina, envolvendo pesquisadora, professora-orientadora e licenciandos, influenciaram a formação de todos e que, certamente, esta é uma pesquisa-formação, na qual, segundo Longarezi e Silva (2013, p. 223),

todos os sujeitos envolvidos participam ativamente do seu processo, investigando situações-problema na busca por construir respostas e soluções para elas; compreende pesquisa acadêmica e prática pedagógica como unidade; é desenvolvida por todos os seus membros mediante discussões e interações diversas; parte das necessidades dos sujeitos envolvidos, dando sentido ao processo que estão vivenciando; ocorre no contexto escolar; toma a prática pedagógica como conteúdo do processo formativo; respeita as diversas formas de saber existentes; e, fundamentalmente, é processo de formação política.

$\mathrm{Na}$ primeira disciplina os licenciandos vivenciaram experiências de ter dois dos sentidos bloqueados, sensibilizando-se com os alunos surdos e cegos. Elaboraram pequenas atividades inclusivas realizadas com os próprios colegas de turma. E puderam trocar experiências e esclarecer dúvidas e angústias com professoras da educação básica que pesquisam e/ou lecionam matemática para alunos com NEE, realizando leituras e discussões teóricas paralelamente.

Na segunda disciplina, principal contexto das análises aqui realizadas, os licenciandos foram divididos em pequenos grupos que, em negociações com escolas e professores,

\footnotetext{
${ }^{4} \mathrm{O}$ projeto de pesquisa foi submetido ao Comitê de Ética em Pesquisa (CEP), tendo sido apreciado e aprovado sob o número CAEE: 18069719.9.0000.5094.
} 
deveriam definir um conteúdo matemático para realizar estudos teóricos, socializar seus resultados e, em seguida, elaborar um plano de aula inovador para turmas regulares com pelo menos um aluno com NEE. Por fim, os licenciandos deveriam realizar regências em escolas públicas ou particulares, no âmbito do estágio ou de outros projetos e programas nos quais estavam envolvidos para implementar essas aulas. Este formato para a disciplina foi pensado para propiciar práticas formativas articuladas com a educação básica e com foco em uma problemática presente no cotidiano escolar - a inclusão de alunos com NEE.

Nesse percurso propusemos leituras sobre a temática da inclusão, abordando o ensino de Matemática para diversas NEE. Essas leituras e estudos subsidiaram os licenciandos para elaborar e implementar os planos de aula, direcionando-os para uma atuação mais informada, em relação à inclusão, nas turmas com alunos com NEE. A preparação e a socialização dos planos de aula aconteceram nas aulas da disciplina, o que possibilitou compartilhar ideias com os colegas, com a pesquisadora, que acompanhou integralmente as aulas dessa disciplina, e com a professora-orientadora. Assim, os planos de aula contaram com valiosas contribuições dos colegas e com a visão crítica da pesquisadora e da professora-orientadora. Portanto, buscamos oportunizar ao futuro professor compreender as diferentes necessidades dos alunos sem ou com NEE; entender a importância de respeitar essas necessidades; e refletir sobre formas de propiciar aprendizagem matemática para todos.

Eram 15 os licenciandos que deveriam se organizar em grupos elaborar e implementar o plano de aula. Estipulamos que cada grupo tivesse pelo menos um licenciando em estágio ou em algum programa de iniciação à docência. Esse aluno deveria negociar o tema a ser desenvolvido no plano de aula com algum professor da escola onde atuava, desde que este tivesse uma turma com pelo menos um aluno com NEE. Se algum grupo formado não contasse com nenhum membro nessas condições, poderia buscar outra forma de parceria.

No Quadro 1 estão as divisões dos grupos com o número de integrantes, o conteúdo do plano de aula elaborado, a série/ano envolvida, o tipo de NEE e o contexto de parceria.

Quadro 11 - Grupos

\begin{tabular}{|c|c|c|c|c|c|}
\hline EQUIPE & INTEGRANTES & CONTEÚDO & ANO & NEE & AMBIENTE \\
\hline ARE $^{5}$ & 3 & Áreas & $6 .^{\circ}$ & 3 TEA $^{6}$ & Estágio \\
\hline PRP & 3 & Ponto, reta e plano & $6 .^{\circ}$ & $\begin{array}{c}3 \mathrm{DI}^{7} \\
1 \mathrm{TEA}\end{array}$ & $\begin{array}{c}\text { Programa Institucional } \\
\text { de Bolsas de Iniciação à } \\
\text { Docência (Pibid) }\end{array}$ \\
\hline CAR & 2 & Plano Cartesiano & $7 .^{\circ}$ & 1 Surdo & \begin{tabular}{c} 
Estágio \\
\hline PNO
\end{tabular} \\
\hline PRO & 4 & Produtos Notáveis & $8 .^{\circ}$ & $\begin{array}{c}4 \text { TDAH }^{8} \\
1 \text { TEA }\end{array}$ & $\begin{array}{c}\text { Parceria com a } \\
\text { professora-pesquisadora }\end{array}$ \\
\hline
\end{tabular}

\footnotetext{
${ }^{5}$ Cada grupo adotou uma sigla, composta pelas iniciais do conteúdo que trabalhou, para facilitar as análises.

${ }^{6}$ Transtorno do Espectro Autista (TEA).

${ }^{7}$ Deficiência Intelectual (DI).

${ }^{8}$ Transtorno de Déficit de Atenção com Hiperatividade (TDAH).
} 
DOI: $10.20396 /$ zet.v29i00.8661777

\begin{tabular}{|l|l|l|l|l|l|}
\hline & & & & & Científica (PIC) \\
\hline
\end{tabular}

Fonte: Elaborado pelas autoras

Cada grupo fez estudos teóricos sobre o conteúdo escolhido, elaborou e implementou um plano de aula. As produções dos licenciandos sobre os estudos teóricos, os planos de aula e uma narrativa do processo de implementação das aulas geraram os dados utilizados. Os licenciandos apresentaram e audiogravaram esses momentos, que complementaram a coleta de dados.

Para analisar os resultados, foram lidas as produções e transcritas as audiogravações buscando relacionar o discurso dos licenciandos com características que evidenciam a mobilização de cada subdomínio do MTSK, conforme registro no referencial teórico sobre o MTSK, assim como o subdomínio específico para Conhecimentos sobre Ensino da Matemática na perspectiva Inclusiva (CEMI), criado por nós para identificar as articulações entre estes conhecimentos e os subdomínios do MTSK. Para isso, elaboramos dois Quadros com os excertos, buscando indiciar Conhecimentos especializados mobilizados pelos licenciandos com destaques das características de cada subdomínio e do CEMI. Para identificar mais de um subdomínio em um excerto, grifamos com cores diferentes cada um. Em seguida, agrupamos tais indícios em novo quadro, com pequenos panoramas dos Conhecimentos mobilizados. Numeramos esses excertos em ordem cronológica das atividades realizadas, e mantivemos aqui essa numeração.

A pesquisa permitiu indicar os conhecimentos privilegiados nesse processo e apontou possíveis lacunas das práticas formativas analisadas: quais Conhecimentos ainda devem ser priorizados na formação inicial, com foco no ensino de matemática na perspectiva inclusiva, em disciplinas específicas da Matemática ou de cunho pedagógico. Optamos por apresentar aqui, na seção seguinte, apenas as análises dos dados coletados pelo grupo ARE.

\section{Conhecimentos especializados mobilizados pelos licenciandos}

Ao expor as análises dos Conhecimentos especializados mobilizados pelos licenciandos do Grupo ARE nesta pesquisa, procuramos destacar seus indícios em negrito, nos excertos aqui transcritos. O grupo ARE, composto por Kim, Lulu e Woody, ${ }^{9}$ abordou em seu plano de aula ${ }^{10}$ o conteúdo de áreas, para uma turma de 23 alunos - sendo três com Transtorno do Espectro Autista (TEA) - do 6. ${ }^{\circ}$ ano do Ensino Fundamental II, em uma escola da rede pública. O grupo realizou todas as atividades propostas, e foram analisados os materiais produzidos por eles e as transcrições das audiogravações em de momentos de preparação e socialização de resultados. Separamos em dois subtópicos as análises das atividades dos licenciandos: (1) momento de estudo e preparação; (2) momento de implementação. Cada subtópico traz dados de diferentes instrumentos de coleta de dados.

\footnotetext{
${ }^{9}$ Para preservar suas identidades, todos os participantes foram identificados com um nome fictício.

${ }^{10}$ Que pode ser acessado no link: https://drive.google.com/file/d/1rVk347wptfUfPaH0fXLd8F6Z8oeqog42/view?usp=sharing
} 
Momento de estudo e preparação

Esse primeiro momento envolveu os estudos teóricos: estudo comparativo das propostas curriculares de Minas Gerais e São Paulo; leitura de 12 livros, sendo 10 livros didáticos (6. ${ }^{\circ}$ ano), 1 paradidático e 1 material pedagógico do professor (7..$^{a}$ série/8..$^{\circ}$ ano); estudo de 1 artigo (Rodrigues \& Bellemain, 2016), sobre o ensino de áreas de figuras planas em diferentes ambientes, com papel e lápis, material manipulativo e o Software Apprenti Géomètre 2. O grupo escolheu o artigo porque buscava uma proposta com diferentes estratégias e metodologias, indicadas por diversas pesquisas como facilitadores da aprendizagem dos alunos com TEA. Essa fase foi concluída com a elaboração do plano de aula, subsidiada pelos estudos realizados. A seguir, trazemos excertos que indicam os conhecimentos mobilizados pelos licenciandos nesses estudos, a cada subdomínio.

KoT - O conhecimento dos tópicos foi mobilizado pelos 3 licenciandos em 12 excertos. Woody apresenta Conhecimento dos Tópicos (KoT) no excerto 3, ao mencionar

aquela tabelinha que tem o metro quadrado, hectômetro, decâmetro, decímetro, metro, milímetro, centímetro e essa tabelinha que eu vejo às vezes os professores reclamando que não serve pra nada [...] ninguém usa [...] é bem aquele conteúdo maçante mesmo e eu acho que nesse sentido ele vai contra as propostas por ser um conteúdo do sexto ano, eu acho que o maior enfoque que as propostas trazem é compreender esses conteúdos, compreender o que é um metro quadrado, é um quadradinho de um metro, mas o metro quadrado pode ser um triângulo desde que o quadradinho de um metro caiba dentro de um triângulo então não é questão de saber transferir de metro quadrado para decâmetro quadrado [ênfase adicionada].

Ao comentar os tópicos abordados, demonstra conhecimento do tema "área" e de seus subtemas, além dos Conhecimentos contidos em manuais. Ele também apresenta características de fenomenologia, sobre as aplicações de matemática, e as exemplifica. E conhece múltiplas definições equivalentes para um mesmo conceito, e utiliza esse exemplo, característica do KoT.

KSM - O conhecimento da estrutura matemática foi mobilizado apenas pelo licenciando Woody em quatro excertos, dos quais destacamos o 35:

Acho muito legal usar o Tangram, aí a gente vai fabricar o Tangram com eles com papel. [...] Ao mesmo tempo que a gente vai tá fazendo o Tangram para trabalhar área a gente também vai tá usando o Tangram para recapitular alguns conceitos de Geometria [ênfase adicionada].

O Conhecimento da Estrutura Matemática foi mobilizado, pois o licenciando destaca que, com o auxílio do Tangram, é possível relacionar o conteúdo que está sendo ensinado áreas - com conceitos anteriores da Geometria, estabelecendo conexões de simplificação.

KPM - O conhecimento da prática matemática esteve em cinco excertos, mobilizados pelos licenciandos Woody e Lulu, e um exemplo pode ser observado no excerto 12, expresso por Lulu: "os livros nos dão um apoio, um suporte, não só mostrando as fórmulas, mas sim mostrando de onde veio, qual a importância daquilo [porém] os livros já dão as fórmulas, o que seria ruim, pensando no lado dos alunos [ênfase adicionada]". 
Ali os licenciandos destacam que os livros mostram de onde vêm as fórmulas, mas sem deixar que os alunos investiguem e deduzam, pois já apresentam as fórmulas prontas e as demonstram. Há indícios do KPM, pois demonstram entender a importância de discutir como se gera o conhecimento matemático.

KMT - O conhecimento do ensino de matemática foi o mais mobilizado pelos licenciandos nesse momento: apareceu 22 vezes. No plano de aula os licenciandos apresentam indícios do KMT, no excerto 37, “com o auxílio do Geoplano, os alunos, em duplas ou trios, deverão criar diferentes retângulos com diferentes áreas, a ideia é que se criem vários para a observação do padrão[ênfase adicionada]".

Os licenciandos mobilizam conhecimento das estratégias e das técnicas, pois sugerem que os alunos trabalhem em duplas ou trios, o que possibilita a inclusão dos alunos com TEA. Demonstram ainda conhecer os recursos, os materiais didáticos e o modo de apresentar o conteúdo e o seu potencial, características do KMT.

KFLM - O conhecimento de características de aprendizagem matemática foi mobilizado 17 vezes, por todos os licenciandos. A licencianda Kim, no excerto 25, ao relatar os resultados do artigo escolhido pelo grupo, argumenta que "eles tinham materiais diferentes, por exemplo, o que tinha manipulativo, eles podiam recortar, copiar, decomposição e sobreposição de figuras, só que para eles o recorte da figura parecia que mudava a área [ênfase adicionada]".

A licencianda apresenta características do KFLM: demonstra conhecer os possíveis modos de aprendizagem dos alunos e refere-se a possíveis dificuldades deles, que acreditavam ser a área de uma figura alterada apenas por recortá-la.

KMLS - O conhecimento dos parâmetros de aprendizagem matemática foi mobilizado 14 vezes, apenas pelos licenciandos Woody e Lulu. Lulu apresenta, no excerto 15, indícios desse conhecimento: "As bases curriculares deram uma orientação e os livros complementaram [ênfase adicionada]".

Fica claro que a licencianda demonstra conhecimento das bases curriculares, ao afirmar que estão presentes nos livros didáticos e que estes a complementam.

CEMI - Foi possível identificar que o conhecimento para o ensino da Matemática na perspectiva inclusiva foi mobilizado duas vezes, apenas pelo licenciando Woody. No excerto 27 há indícios desse conhecimento.

Mas os materiais manipulativos ajudariam muito tanto com o aluno com TEA quanto os outros alunos a realizar as atividades que a gente pretende e isso de fazer em dupla também traz a interação com outros alunos que é muito importante para o aluno com TEA, porque ele tem dificuldade, dois dos alunos com TEA nossos têm muita dificuldade [ênfase adicionada].

O conhecimento do ensino da matemática para o aluno com TEA é mobilizado quando o licenciando alerta sobre a necessidade de materiais manipulativos para bem atender suas necessidades. Revela articular os modos de apresentar o conteúdo e as estratégias e 
DOI: 10.20396/zet.v29i00.8661777

técnicas características do KMT e perceber que as vantagens desse material não se limitam ao aluno com TEA, o que pode denotar uma perspectiva mais ampla de inclusão.

Síntese dos Conhecimentos especializados mobilizados durante o primeiro momento

O Quadro 2 expõe a distribuição de excertos de acordo com os subdomínios mobilizados, com destaque em negrito para o CEMI, porque ele se articula com os demais subdomínios.

Quadro 22 - Distribuição dos excertos do momento de estudo/preparação

\begin{tabular}{|c|c|l|}
\hline Domínio & Subdomínio & \multicolumn{1}{|c|}{ Excertos } \\
\hline \multirow{3}{*}{ MK } & KoT & $3,5,7,16,17,20,22,24,28,29,34$ e 36 \\
\cline { 2 - 3 } & KSM & $6,33,35$ e 37 \\
\cline { 2 - 3 } & KPM & $3,12, \mathbf{1 3}, 28$ e 38 \\
\hline \multirow{4}{*}{ PCK } & KMT & $\begin{array}{l}1,4,5,6,7,8,13,14,15,17,19,21,23,25,26,27,30,32,34, \\
35,36 \text { e 39 }\end{array}$ \\
\cline { 2 - 3 } & KFLM & $7,8,10,11,12, \mathbf{1 3}, 14,16,17,18,21,22,24,25,26,32$ e 39 \\
\cline { 2 - 3 } & KMLS & $1,3,4,5,6,7,8,15,29,30,31,32,33$ e 38 \\
\hline
\end{tabular}

Fonte: Elaborado pelas autoras

Os dados analisados mostram que os Conhecimentos especializados mobilizados pelo grupo ARE se manifestaram em maior parte no domínio do PCK. Além disso, o KMT foi o que mais apareceu, pois o grupo fez um estudo sobre os materiais e também preparou as aulas com recursos e materiais. Em contrapartida, o conhecimento menos mobilizado foi o KSM, o que pode indicar que o fato de eles terem preparado as atividades para um conteúdo isolado, numa turma em que tiveram um breve contato, dificultou o estabelecimento de relações com outros conteúdos.

O KFLM, relacionado aos modos de aprendizagem dos alunos, foi bastante mobilizado, tendo em vista a exigência de pensar atividades que atendessem às necessidades dos alunos com TEA. Este é um indício de que o estudo das propostas de ensino, com foco nas necessidades dos alunos com TEA, mobiliza esse tipo de conhecimento. O KMLS representa os Conhecimentos acerca dos documentos curriculares, também bastante mobilizado, pois os licenciandos estudaram propostas curriculares. Quanto ao CEMI, embora tenha sido pouco mobilizado (apenas em dois excertos), nota-se que ele aparece em três subdomínios, que relacionam o fato de colocar esse aluno como centro do processo (KPM), observando os recursos necessários (KMT) para que ele possa aprender com significado (KFLM).

\section{Momento de implementação}

Esse momento integra o processo de implementação das aulas, cuja análise se deu a partir do relato oral e da narrativa escrita pelos licenciandos. Com a mesma organização do item anterior, traremos aqui alguns excertos mobilizados pelos licenciandos, conforme os subdomínios.

KoT - O conhecimento dos tópicos foi mobilizado em cinco excertos presentes na 
narrativa. $\mathrm{O}$ excerto 50 menciona algumas de suas características:

Daí conseguimos extrair, com mais intensidade, o conceito de unidade de medida padrão, dizendo aos alunos que a medida da área muda de valor dependendo da unidade de medida que usamos e assim foi possível explicar sobre o metro quadrado, seus múltiplos e submúltiplos, e o porquê de, em diferentes superfícies, usarmos diferentes unidades de medida [ênfase adicionada].

Há indícios de conhecimento das propriedades e dos fundamentos atribuídos a um tópico e dos temas ensinados e os seus subtemas: os licenciandos explicam o conceito de unidade de medida padrão, demonstram conhecer múltiplas definições equivalentes para um mesmo conceito e, ao explicar o porquê de se fazer assim, apresentam características dos resultados.

KPM - O conhecimento da prática matemática foi mobilizado apenas nos excertos 52 e 54, extraídos da narrativa. Como eles estão relacionados, apresentamos ambos.

Essa era a atividade que mais parecia dar certo e, de fato, contribuiu muito para a sala, já que era uma atividade de cunho investigativo e observação de padrões, onde os alunos deveriam tratar as informações de uma tabela criada por eles mesmos [ênfase adicionada].

A criação da tabela, como mostra a Figura 6, proporcionou que alunos conseguissem enxergar o padrão para seu preenchimento. Os alunos fizeram a atividade em grupo e era possivel ver alguns grupos afirmando "ah é só fazer vezes", indicando que bastava multiplicar base e altura para encontrar o valor da área [ênfase adicionada].

Nestes dois excertos os licenciandos apresentaram indícios de KPM, pois permitiram que os alunos, pela construção de uma tabela, percebessem padrões e concluíssem que a área é calculada pela multiplicação da base pela altura. Revelaram conhecer como se gera o conhecimento matemático. Optamos por classificar esse conhecimento como KPM, mas, ao adaptar o conhecimento da prática matemática para o ensino, os licenciandos mobilizam também conhecimentos pedagógicos de conteúdo.

KMT - O conhecimento do ensino de matemática foi evidenciado em 11 excertos. No excerto 53, analisamos algumas características:

O princípio da atividade era o seguinte: no Geoplano os alunos construíam retângulos de dimensões a suas escolhas, depois, numa tabela pré-montada, preenchiam, na primeira coluna o comprimento da base, na segunda coluna o comprimento da altura e na terceira a área do retângulo. É importante perceber, que esse material facilita muito identificar esses dados, já que para medir os comprimentos bastava olhar para os pinos do material e para medir a área bastava ver quantos quadrados existiam dentro do retângulo criado [ênfase adicionada].

Nesse excerto os licenciandos revelam conhecer os recursos e os materiais didáticos, como o Geoplano. E, ao utilizarem esse recurso dentro de uma atividade contextualizada com o conteúdo que está sendo ensinado e afirmarem que o material facilita a identificação dos dados, demonstram ter conhecimento do seu potencial. As técnicas apresentadas pelos licenciandos também se configuram como características do KMT. 
KFLM - O conhecimento de características de aprendizagem matemática se apresentou em dez excertos das narrativas, entre eles o 46:

Neste momento notamos que esta aluna, e mais alguns outros, tentavam usar a ideia de decomposição, mesmo não tendo sido explicado esse método, o que nos deixou bastante contentes por ver que eles mesmos estavam construindo o conhecimento $e$ que, assim, teria mais significado no momento em que fôssemos corrigir e formalizar o conceito [ênfase adicionada].

Os licenciandos apresentam indícios de conhecer os possíveis modos de aprendizagem dos alunos, ao relatar seus raciocínios, e características dos processos e das estratégias desses. Revelam conhecimento de formas de interagir com o conteúdo, ao alegrar-se com o uso, pelos alunos, de uma estratégia não apresentada a eles formalmente. Talvez o que tenha auxiliado é que os alunos puderam conhecer essas estratégias em séries anteriores - por exemplo, ao lidar com as operações básicas.

KMLS - Indícios de conhecimento dos parâmetros de aprendizagem matemática despontam em dois excertos, entre eles o 56, referente à fala de Woody na apresentação da narrativa:

Na prova normal eles tinham a tabela e tinham que completar se era multiplicado ou dividido por 10, pra usar ela, porque a gente não achou justo que os alunos decorassem quilômetro, hectômetro, decâmetro, porque essa sequência eles nunca vão decorar [ênfase adicionada] [...].

A explicação do licenciando sobre a manifestação do grupo demonstra conhecer o que um aluno deve aprender, o nível de profundidade e a maneira como se espera que o estudante aprenda.

CEMI - O conhecimento para o ensino da Matemática na perspectiva inclusiva foi mobilizado oito vezes, como indicia o excerto 56 :

Na prova normal eles tinham a tabela e tinham que completar se era multiplicado ou dividido por 10, pra usar ela, porque a gente não achou justo que os alunos decorassem quilômetro, hectômetro, decâmetro, porque essa sequência eles nunca vão decorar. [...] Aí chegou na atividade de área, a primeira tinha a unidade padrão e aí eles tinham que comparar a área da figura usada, aí tem a tabela de conversão de unidade de área, dois exercícios só pra converter e um exercício que usava medida agrária. [...] Aí pros alunos com TEA [...] a gente pediu pra eles medirem a mesa com a mão e medir a mão deles e aí ver quanto que a mesa media de comprimento. [...] a gente levou os blocos pra eles medirem o perímetro das figuras e na parte de áreas eles usavam o Geoplano para construir o retângulo e calcular a área do retângulo usando o material [ênfase adicionada].

Os licenciandos se preocuparam em levar uma prova adaptada para os alunos com TEA, já que possuem uma limitação, se comparados aos demais alunos. Está claro que mobilizaram o Conhecimento sobre o Ensino da Matemática para os alunos com NEE, de forma articulada com o conhecimento sobre os modos de apresentar o conteúdo e o seu potencial, com o conhecimento acerca dos recursos e dos materiais didáticos, das estratégias e técnicas utilizadas, características também do KMT. 
DOI: 10.20396/zet.v29i00.8661777

Síntese dos Conhecimentos especializados mobilizados no momento de implementação

O Quadro 3 contém a distribuição de excertos desse momento de implementação do grupo ARE, de acordo com os subdomínios mobilizados. Os negritos se referem ao subdomínio CEMI, relacionado com os demais.

Quadro 33 - Distribuição dos excertos do momento de implementação

\begin{tabular}{|l|l|l|}
\hline Domínio & Subdomínio & \multicolumn{1}{|c|}{ Excertos } \\
\hline \multirow{3}{*}{ MK } & KoT & $\mathbf{4 1}, \mathbf{4 3}, 44,47,48$ e 50 \\
\cline { 2 - 3 } & KSM & - \\
\cline { 2 - 3 } & KPM & 52,54 \\
\hline \multirow{3}{*}{ PCK } & KMT & $\mathbf{4 1}, \mathbf{4 2}, 44,45,47,48,49,50,52,53$ e $\mathbf{5 6}$ \\
\cline { 2 - 3 } & KFLM & $\mathbf{4 0}, \mathbf{4 3}, 45,46,47, \mathbf{4 9}, 50,51,54$ e 55 \\
\cline { 2 - 3 } & KMLS & $\mathbf{5 6}$ e $\mathbf{5 7}$ \\
\hline
\end{tabular}

Fonte: Elaborado pelas autoras

Os dados produzidos neste momento novamente mostraram que os Conhecimentos especializados, mobilizados pelo grupo ARE, estiveram em maior parte no domínio do PCK. E o KMT foi o mais evidenciado, pois os licenciandos utilizaram recursos, materiais e estratégias para a implementação das aulas. O KFLM também foi mobilizado um número significativo de vezes, pois relaciona-se aos modos de aprendizagem dos alunos, os quais foram foco da narrativa das aulas, que analisou o processo de seu desenvolvimento das atividades. Nota-se que nesse momento de implementação o CEMI é mais mobilizado devido ao contato direto com os alunos com NEE, aparecendo em quatro dos cinco subdomínios mobilizados.

Já o KMLS e KPM não foram tão evidenciados como no momento anterior, pois, no processo de implementação, a preocupação está mais direcionada a aprendizagem dos alunos, e não mais às propostas curriculares e à prática matemática. Nesse momento de implementação, o KSM não é mobilizado, devido ao fato de não serem pensadas relações com outros conteúdos.

\section{Considerações Finais}

O pequeno recorte apresentado evidencia que a proposta da disciplina despertou nos licenciandos interesse e preocupação com a necessidade de se prepararem de forma adequada para ensinar matemática a alunos com NEE, pois os futuros professores mobilizaram muitos conhecimentos, em especial conhecimentos pedagógicos de conteúdo, de forma relacionada com a inclusão (CEMI). Eles se mostraram dispostos a procurar métodos e materiais que facilitem a aprendizagem desses alunos, procuraram coloca-los no centro do processo de aprendizagem e puderam refletir sobre as limitações desses materiais, já que nem todos os conteúdos matemáticos podem ser ensinados com os recursos existentes, o que exige continuar criando. No momento de implementação o CEMI se torna ainda mais evidente, mostrando a importância de discutir as NEE, e de promover a articulação entre universidade e escola, nos cursos de licenciatura em Matemática, para que o futuro professor relacione 
conhecimentos matemáticos e conhecimentos pedagógicos de conteúdo com conhecimentos sobre NEE, de forma a tornar significativo o ensino para estes alunos e para os demais.

A análise revelou que os conhecimentos mais mobilizados estavam relacionados ao PCK, o que indica uma preocupação da disciplina em desenvolver Conhecimento Pedagógico de Conteúdo, sem desvincular dos Conhecimentos Matemáticos, e em articulação com os Conhecimentos específicos para o Ensino de Matemática na Perspectiva Inclusiva. A vivência na educação básica, em um contexto de aplicação dos planos de aula desenvolvidos, porém de forma articulada com as necessidades do planejamento do professor e levando em conta as necessidades de todos alunos, em especial daqueles com NEE, possibilitou uma experiência também de articulação entre o conhecimento do conteúdo e o conhecimento pedagógico desse conteúdo, ou seja, na forma como apresentar para os alunos.

Embora reconheçamos as limitações da formação inicial, práticas formativas como esta podem tornar o professor mais preparado para atuar na diversidade de contextos que a escola apresenta. Assim, evidencia-se a necessidade de disciplinas que tratem dos dois domínios (MK e PCK), de forma vinculada, para que o professor atue com competência.

Para finalizar, cabe apontar que o fato de o KSM ter sido pouco evidenciado, além de estar relacionado ao fato dos licenciandos prepararem um único conteúdo, para um momento breve com a turma, pode indicar que uma disciplina que adota práticas formativas com foco na inclusão ou mesmo outras disciplinas pedagógicas que tomem como foco a prática como componente curricular nem sempre vão mobilizar todos os subdomínios do MTSK. Tendo em vista que os licenciandos cursam disciplinas específicas da Matemática, nas quais a estrutura da matemática é o foco principal, nessas disciplinas esses conhecimentos podem ser mais mobilizados. Isso nos permite questionar: que possibilidades esses futuros professores terão de articular o conhecimento dos conteúdos da Matemática acadêmica com a Matemática escolar (Moreira e David, 2013), caso essas disciplinas não problematizem, também, a prática como componente curricular?

\section{Referências}

Ball, D. L., Thames, M. H., \& Phelps, G. (2008). Content knowledge for teaching: what makes it special. Journal of Teacher Education, 59(5), 389-407.

Bernardo, R., Policastro, M. S., Almeida, A. R., Ribeiro, M., Melo, J. M., \& Aiub, M. (2018). Conhecimento matemático especializado de professores da educação infantil e anos iniciais: conexões em medidas. Cadernos Cenpec, 8(1), 98-124.

Brasil. Lei no 9394, de 20 de dezembro de 1996. (1996). Fixa Lei de Diretrizes e Bases da Educação Nacional.

Brasil. Conselho Nacional de Educação (CNE/CP). (2001). Resolução $n^{\circ} 2$, de 11 de setembro de 2001. Institui Diretrizes Curriculares Nacionais para a Educação Especial na Educação Básica. Diário Oficial República Federativa do Brasil, Brasília.

Brasil. Decreto $n^{o} 7611$ de 17 de novembro de 2011. (2011). Dispõe sobre a educação especial, o atendimento educacional especializado e dá outras providências. 
DOI: 10.20396/zet.v29i00.8661777

Carrillo, J., Climent, N., Contreras, L. C., \& Muñoz-Catalán, M. D. C. (2013). Determining specialised knowledge for mathematics teaching. Proceedings of the CERME, 8, 29852994.

Flores-Medrano, E., Escudero-Ávila, D., Montes, M., Aguilar, A., \& Carrillo, J. (2014). Nuestra modelación del conocimiento especializado del professor de Matemáticas, el MTSK. In M. A. Montes, E. Carmona, A. Aguillar-González \& J. Carrillo, Un marco teórico para el Conocimiento especializado del Professor de Matemáticas (pp. 71- 93). Huelva: Universidad de Huelva.

Flores-Medrano, E., Montes, A. M., Carrillo, J., Contreras, L. C., Muñoz-Catalãn, M. C., \& Liñán, M. M. (2016). El papel del MTSK como modelo de conhecimento del profesor en las interrelaciones entre los espacios de trabajo matemático. Bolema, 30(54), 204-221.

Goldenberg, M. (2004). A arte de pesquisar: como fazer pesquisa qualitativa em ciências sociais. Rio de Janeiro: Record.

Longarezi, A. M., \& Silva, J. L. (2013). Pesquisa-formação: Um olhar para sua constituição conceitual e política. Revista Contrapontos, 13(3), 214-225.

Lüdke, M., \& André, M. E. D. A. (2013). Pesquisa em educação: abordagens qualitativas. Rio de Janeiro: EPU, 2013.

Moreira, P. C., \& David, M. M. M. (2013). Formação matemática do professor: licenciatura e prática docente escolar. Belo Horizonte: Autêntica.

Pacheco, M. B., \& Andreis, G. S. L. (2018). Causas das dificuldades de aprendizagem em Matemática: percepção de professores e estudantes do $3^{\circ}$ ano do Ensino Médio. Revista Principia, 38, 105-119.

Passos, A. A., Passos M. M., \& Arruda S. M. (2013). A Educação Matemática inclusiva no Brasil: uma análise baseada em artigos publicados em revistas de Educação Matemática. Revista Brasileira de Ensino de Ciência e Tecnologia, 6(2), 1-22.

Ribeiro, C. M. S. (2020). Conhecimento interpretativo de professores de Matemática e suas especificidades para o ensino - uma necessidade de mudança de foco na formação de professores. Palestra. In XII Workshop de Verão em Matemática, Departamento de Matemática, Universidade de Brasília.

Ribeiro, C. M., \& Amaral, R. (2015). Early year's prospective teachers' specialized knowledge on problem posing. Proceedings of PME, 39, 81-88.

Ribeiro, G. G. (2018). (Como) a temática da inclusão tem sido abordada na formação inicial do professor de Matemática? Anais do IV Congresso Nacional de Formação de Professores. Águas de Lindóia: Unesp. Retirado em 29 de outubro de 2020, de https://sigeve.ead.unesp.br/index.php/submissionProceedings/viewSubmission?trabalhoI $\mathrm{d}=2141$.

Rodrigues, A. D., \& Bellemain, P. B. B. (2016). A comparação de áreas de figuras planas em diferentes ambientes: papel e lápis, materiais manipulativos e no Apprenti Géomètre 2. Em Teia, 7(3), 1-25.

Shulman, L. S. (1987). Knowledge and teaching: foundations of a new reform. Harvard Educational Review, 57(1), 1-22. 
DOI: 10.20396/zet.v29i00.8661777

Souza, A. P. (2016). Um mapeamento da inserção da inclusão nos cursos de formação inicial de professores de Matemática nas universidades federais do estado de Minas Gerais e no Instituto Federal do Sul de Minas Gerais. Dissertação de Mestrado Profissional em Ensino de Ciências. Itajubá: Universidade Federal de Itajubá. Retirado em 01 de fevereiro, 2020, de: https://repositorio.unifei.edu.br/xmlui/handle/123456789/606?localeattribute $=$ es. 